\title{
SIDA : variabilité génétique du virus et progression de l'épidémie
}

Variabilité génétique du virus HIV. Les nouvelles des derniers mois concernant l'épidémie de SIDA et la biologie du virus (dont le nouveau nom proposé par un Comité international de nomenclature est "Human Immunodeficiency Virus, ou HIV) ne sont pas très bonnes.

Tout d'abord des données récentes confirment la très grande variabilité génétique du virus, chez plusieurs malades mais aussi chez un même malade au cours du temps [I-3]. La glycoprotéine de surface, codée par le gène env est la plus intéressée par cette variabilité, encore qu'elle contienne des régions hypervariables et d'autres plus conservées. Les plus grandes variations de séquence sont certes observées entre des isolats différents (par exemple africains, européens ou nord-américains $[I, 2])$, mais des mutations du gène env apparaissent aussi aux différents stades de l'infection de malades donnés [3]. Cette variabilité génétique n'est d'ailleurs pas propre au virus HIV mais est caractéristique du cycle rétroviral qui nécessite l'utilisation de trois enzymes différentes pour la replication: l'ADN polymérase de l'hôte pour la replication de l'ADN proviral, la transcriptase reverse virale pour la synthèse de l'ADN proviral à partir de l'ARN génomique viral et l'ARN polymérase de l'hôte pour la synthèse d'ARN viral à partir de l'ADN proviral intégré. Seule la première de ces enzymes est d'une très grande fidélité, la transcriptase reverse provoquant un taux d'erreurs dans la replication beaucoup plus élevé. On estime ainsi à 8-10 le nombre moyen d'erreurs s'accumulant au cours d'un cycle complet de replication d'un rétrovirus ayant un génome de 7 à $10 k b$ [I]. Les variations antigéniques consécutives à cette variabilité génétique interviennent très probablement dans la résistance des rétrovirus (notamment des lentivirus du type du virus de Visna ou du HIV) à l'égard de la défense immunologique des organismes $m / s n^{\circ} 8$, vol. 2, octobre 86 infectés: les anticorps développés ne reconnaissent plus l'antigène de surface $d u$ fait de sa variation. Il va de soi que ces phénomènes posent de redoutables problèmes aux chercheurs s'efforçant de développer des vaccins efficaces : ceux-ci devront en effet être dirigés de préférence contre des régions conservées de l'antigène de surface, tout en étant neutralisants, ce qui exige que ces régions conservées soient accessibles et fonctionnellement importantes. Seule cette dernière condition paraît être fortement probable: la conservation génétique signant pratiquement limportance fonctionnelle des zones conservées. Il est en revanche hautement vraisemblable que les zones hypervariables sont les plus exposées à la surface du virus, formant en quelque sorte une ombrelle de protection des régions conservées essentielles à l'infection virale $[I]$.

Progression de l'épidémie: une statistique inquiétante de l'armée américaine. La presse d'information a largement rendu compte des statistiques concernant l'inquiétante progression de l'épidémie de SIDA en Afrique centrale où la transmission de la maladie se fait principalement par contact hétérosexuel. Des chiffres récemment présentés par l'armée américaine (conférence internationale sur le SIDA, Paris, Fuin I986) ont par contre fait l'objet de moins de commentaires; ils sont cependant assez inquiétants. Les militaires américains ont recherché depuis octobre 1985 des anticorps anti HIV chez 300000 personnes candidates au recrutement, 260000 hommes et 40000 femmes de 18 à 25 ans. La fréquence de l'homosexualité dans cette population apparaît faible, celle de l'utilisation de drogue n'étant pas précisée mais ne semblant pas particulièrement haute par rapport à la population générale. Alors que la fréquence de positivité reste très faible dans des zones rurales (Idaho, Montana, Nord et Sud Dakota), elle atteint I candidat au recrutement sur
50 à Manhattan, et presque aussi fréquemment les jeunes hommes que les jeunes femmes. Dans New York city en général les fréquences de positivité sont de I/I25 chez les hommes et $1 / 167$ chez les femmes. Dans l'ensemble de l'étude le rapport hommel femme positif est de 2,5, alors que dans la population américaine générale il est de 13, l'incidence de positivité étant de $1 / 2500$.

Ces résultats indiquent que dans les grandes villes américaines la proportion d'adultes jeunes ayant été en contact avec le virus a beaucoup augmenté et, qu'à partir d'une certaine fréquence de positivité, la prévalence de certains groupes (homosexuels, drogués) et des hommes parmi les sujets-contacts s'estompe, la transmission devenant alors principalement hétérosexuelle... comme en Afrique. L'étude de couples mariés particuliers semble d'ailleurs indiquer que le risque d'infection d'un partenaire sain par un partenaire porteur est de $50 \%$... quelque soit le sexe du premier partenaire atteint.

Reste à connaître la proportion des sujets porteurs qui développeront la maladie : là encore c'est l'inquiétude qui prévaut, le sentiment actuel étant que le risque de développer un SIDA dans les 6-8 ans qui suivent la découverte d'anticorps anti $H I V$ est de l'ordre de 20 à $35 \%$... la révision de ce chiffre à mesure que sont dépouillées les statistiques se faisant plutôt vers le haut. Ainsi en matière de SIDA l'ampleur des efforts actuellement consentis pour parvenir à une prévention ou à un traitement de la maladie semble bien en rapport avec la montée des périls.

A.K.

I. Coffin JM. Genetic variation in AIDS viruses. Cell 1986; 46 : I-4.

2. Alizon M, Wain-Hobson S, Montagnier L, Sonigo $P$. Genetic variability of the AIDS virus: nucleotide sequence analysis of two isolates from af rican patients. Cell 1986; 46: 63-74.

3. Hahn BH, Shaw GM, Taylor ME, et al. Genetic variations in HTLV III/LAV over time in patients with AIDS or at risk for AIDS. Science 1986; 232: 1548-53. 